\title{
Safety and Effectiveness of Bolus Insulin Aspart in People with Type 2 Diabetes: $A_{1}$ chieve Sub-Analysis
}

\author{
Hoosen Randeree • Andreas Liebl • Issam Hajjaji • \\ Mohammad Khamseh • Lenita Zajdenverg • \\ Jian-Wen Chen · Jihad Haddad
}

To view enhanced content go to www.diabetestherapy-open.com

Received: April 10, 2013 / Published online: June 12, 2013

(c) The Author(s) 2013. This article is published with open access at Springerlink.com

\begin{abstract}
Introduction: This sub-analysis evaluated clinical safety and effectiveness of bolus insulin aspart [with/without oral glucoselowering drugs (OGLDs)] as the only insulin therapy.
\end{abstract}

Methods: $\mathrm{A}_{1}$ chieve was an international, multicenter, prospective, open-label, noninterventional, observational, 24-week study in

The $\mathrm{A}_{1}$ chieve trial was registered with ClinicalTrials.gov (NCT00869908).

H. Randeree

Parklands Medical Centre, Durban, KwaZulu-Natal, South Africa

A. Liebl

Centre for Diabetes and Metabolism, Fachklinik Bad Heilbrunn, Bad Heilbrunn, Bavaria, Germany

I. Hajjaji

National Centre for Diabetes \& Endocrinology,

Tripoli, Libya

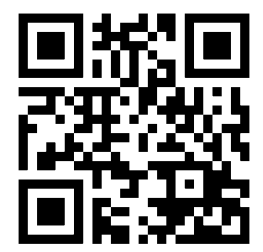

Enhanced content for this article is

available on the journal web site:

www.diabetestherapy-open.com people with type 2 diabetes mellitus starting/ switching to biphasic insulin aspart 30, insulin detemir or insulin aspart treatment (alone/in combination) in routine clinical practice. This sub-analysis evaluated clinical safety and effectiveness of bolus insulin aspart ( \pm OGLDs) as the only insulin therapy. Data were analyzed for all patients, insulin-experienced and insulinnaive sub-groups, and sub-groups defined by the number of OGLDs prescribed at baseline (no OGLDs, one OGLD or $\geq$ two OGLDs). Safety and effectiveness endpoints were assessed at baseline and following 24 weeks' therapy.

M. Khamseh

Endocrine Research Centre (Firouzgar), Institute of Endocrinology \& Metabolism, Tehran University of Medical Sciences, Tehran, Iran

\section{Zajdenverg}

Internal Medicine Department/Diabetes Program, Hospital Universitário Clementino Fraga Filho, Federal University of Rio de Janeiro (UFRJ), Rio de Janeiro, Brazil

J.-W. Chen $(\bowtie)$

Novo Nordisk Health Care AG, Thurgauerstrasse 36/38, 8050 Zurich, Switzerland e-mail: jwch@novonordisk.com

J. Haddad

Division of Endocrinology, Prince Hamazah Hospital, Amman, Jordan 
Results: In total, 2,026 patients were included (insulin-experienced, $n=561$; insulin-naive, $n=1,465)$ in this sub-analysis. Significant improvements from baseline after 24 weeks' treatment with insulin aspart \pm OGLDs were observed across all sub-groups for: glycated hemoglobin (range of means across sub-groups -1.6 to $-2.4 \% ; p<0.001$ for all comparisons), fasting plasma glucose $(-2.5$ to $-3.8 \mathrm{mmol} / \mathrm{l}$; $p<0.001$ for all comparisons), post-breakfast post-prandial glucose $(-3.4$ to $-5.8 \mathrm{mmol} / \mathrm{l}$; $p<0.001$ for all comparisons), and healthrelated quality of life (HRQoL; $p<0.001$ for all comparisons). The proportion of patients reporting hypoglycemia events was significantly reduced from baseline after 24 weeks (insulin-naive cohort: 7.9-2.8\%; $p<0.001$; insulin-experienced cohort: $23.2-7.8 \% ; p<0.001)$. There were no reports of major hypoglycemia events at 24 weeks; risk of nocturnal hypoglycemia was $<0.6$ events/ person-year. No serious adverse drug reactions were reported.

Conclusion: Insulin aspart \pm OGLDs is associated with significant improvements in glycemic control and HRQoL, without increased risk of hypoglycemia, in people with type 2 diabetes and sub-optimal glucose control.

Keywords: $A_{1}$ chieve study; Bolus only; Insulin aspart; Oral glucose-lowering drugs; Type 2 diabetes

\section{INTRODUCTION}

Increased life expectancy and high global prevalence of type 2 diabetes mellitus $[1,2]$ render treatment of this condition a lifelong personal and social burden [3-5]. Post-prandial hyperglycemia is a common phenomenon in people with type 1 and 2 diabetes, and incurs a significant risk of diabetes-related complications [6]. Therefore, achieving control of post-prandial glucose (PPG) level and fasting plasma glucose (FPG) level is important to maintain glycated hemoglobin $\left(\mathrm{HbA}_{1 \mathrm{c}}\right)$ levels below target [6]. Despite the need to control PPG, the number of available drugs able to accomplish this is limited. Conventional oral glucose-lowering drugs (OGLDs) and lifestyle modifications, while fundamental to early management of the disease, are unable to maintain good glycemic control in the longer term, and there is a consequent additional requirement for exogenous insulin $[7,8]$.

Compared with exogenous human insulin, the rapid-acting analog insulin aspart (NovoRapid $^{\circledR}$; Novo Nordisk A/S, Bagsvaerd, Denmark) is associated with rapid absorption and early onset of action, which facilitates administration immediately before or shortly after a meal [9]. Subcutaneous administration of rapid-acting insulin analogs results in a physiologic profile that bears a closer resemblance to endogenous insulin than is achieved with subcutaneous administration of human insulin. By virtue of this action, insulin analogs, such as insulin aspart, offer advantages over human insulin (e.g., greater convenience [10]) and have the potential to reduce PPG excursions, thereby improving overall glycemic control [11, 12]. Clinical research shows that insulin aspart is also associated with reduced hypoglycemia risk and greater treatment satisfaction versus human insulin when administered in a basal-bolus regimen among people with type 1 and 2 diabetes mellitus [1318]. Guidelines generally recommend initiating insulin therapy when OGLDs fail to provide adequate glycemic control [19]; in this context, some healthcare professionals start patients on prandial insulin as the only insulin therapy [20, 21]. While few studies have examined the safety 
and effectiveness of bolus-only insulin aspart, particularly as add-on to OGLDs, available evidence suggests beneficial effects on glycemic control when OGLD therapy is insufficient [22].

While well-designed randomized controlled trials provide a stringent way of assessing insulin regimens, they focus on a selected patient group under intensive clinical supervision. Therefore, results obtained from such studies may not be truly representative of routine clinical practice. In addition, randomized controlled trials are often performed in restricted geographical regions, with less focus on those countries that are less well resourced. While observational studies are associated with limitations, such as lack of a control group, they are capable of enrolling a larger cohort of people from diverse geographic locations and environments, and may better represent everyday clinical practice than randomized controlled trials.

$\mathrm{A}_{1}$ chieve was an international observational study evaluating the safety and effectiveness of insulin analogs in people with type 2 diabetes mellitus receiving routine clinical care in 28 countries across four continents [20]. This subgroup analysis of participants from the $A_{1}$ chieve study aimed to investigate the clinical safety and effectiveness of insulin aspart alone or as add-on to OGLDs for the management of type 2 diabetes mellitus in routine clinical practice.

\section{MATERIALS AND METHODS}

\section{Study Design}

$\mathrm{A}_{1}$ chieve was a 24-week, international, prospective, multicenter, non-interventional, observational study examining the safety and effectiveness of insulin analogs in 66,276 people with type 2 diabetes mellitus undergoing treatment in routine clinical practice between January 2009 and June 2010 [20]. The study was conducted across 3,166 centers in 28 countries, representing seven geographical regions: China, South Asia (Bangladesh, India, Pakistan), East Asia (Indonesia, Korea, Malaysia, Philippines, Singapore, Taiwan), North Africa (Algeria, Morocco, Tunisia, Libya), Middle East (Egypt, Iran, Jordan, Turkey, Bahrain, Kuwait, Oman, Qatar, Saudi Arabia, UAE, Yemen), Latin America (Argentina, Mexico), and Russia.

Insulin analogs (manufactured by Novo Nordisk A/S, Bagsvaerd, Denmark) were used in accordance with the label approved by the regulatory authority, and all local requirements for Health Authorities or Ethics Committee approvals were obtained, if applicable. Physicians were able to adjust treatment during the 24 weeks. Details on inclusion and exclusion criteria, and study design have been reported elsewhere [20]. In every country, participants gave informed consent and were free to withdraw from the study at any time. The study was conducted in accordance with the Declaration of Helsinki of 1964, as revised in 2008 [23], and Guidelines for Good Pharmacoepidemiology Practice [24].

Results presented here are from a subanalysis of patients treated with insulin aspart alone or in combination with OGLDs (excluding those who received basal-bolus insulin regimens).

\section{Assessments}

Assessments were at baseline (time when the treating physician prescribed insulin aspart), approximately 12 weeks after baseline (results not reported here), and study end (approximately 24 weeks after baseline). 
The primary objective of the study was to evaluate the safety profile of insulin analogs by measuring the incidence of serious adverse drug reactions (SADRs), including major hypoglycemia events. Other safety assessments included change in the number of hypoglycemia events between baseline and 24 weeks (reported as the percentage of patients reporting an event and events/person year). These were based on patient recall of events within the preceding 4 weeks of the study visit.

Effectiveness of therapy was determined from measurements made by the treating physician team at each assessment visit; data were collated into a standard case report form using information from the physicians' clinical notes and the participants' recall and self-monitoring diary/meter. Effectiveness outcomes included change from baseline after 24 weeks in glucose control measures $\left[\mathrm{HbA}_{1 \mathrm{c}} ; \quad\right.$ FPG (pre-breakfast), and PPG (90-120 min after beginning breakfast)], body weight, and health-related quality of life (HRQoL). HRQoL was measured at baseline and after 24 weeks by self-report using the EQ5D questionnaire [25], which evaluates five domains of patient health/lifestyle (mobility, self-care, usual activities, pain/discomfort, and anxiety/depression). The questionnaire also includes a rating for an individual's current HRQoL on a visual analog scale [VAS; ranging from 0 (worst imaginable health) to 100 (best imaginable health)]. Scores in the five domains were converted to a single utility value (UK VAS set), with '1.00' indicating 'full health' and '0.00' indicating 'deceased' [26, 27].

Due to the non-interventional design of the analysis and lack of protocol enforcement to report all outcomes, data are described here as per available reports.

\section{Statistical Analyses}

Analyses were performed on data from all patients with a baseline visit who were treated with insulin aspart at least once during the study. For those patients who withdrew from the study, data collected until the date of withdrawal were used for analysis. Patients were split into two cohorts according to whether they had received insulin before the study (insulin-experienced and insulin-naive) or not. Sub-group analyses were then conducted in each cohort according to the number of OGLDs received at baseline (none, one, or $\geq$ two).

Changes from baseline in effectiveness measures were assessed using Student's paired $t$ test. For hypoglycemia, the percentage of patients reporting at least one event was analyzed using McNemar's test. All statistical analyses were two-sided, using a pre-specified $5 \%$ significance level, and were performed by Novo Nordisk A/S using SAS ${ }^{\circledR}$ Version 9.1.3 (SAS ${ }^{\circledR}$ Institute Inc., Cary, NC, USA).

\section{RESULTS}

\section{Study Participants}

In total, 3,898 patients from the $A_{1}$ chieve study received treatment with insulin aspart alone or in combination with OGLDs at baseline (insulin aspart alone, $n=1,560$; insulin aspart + one OGLD, $n=1,514$; and insulin aspart $+\geq$ two OGLDs, $n=824$ ) [20]. Of these, 1,872 patients subsequently switched to insulin analog basalbolus regimens, basal insulin analog regimens, or biphasic insulin analog regimens before completing the study. Thus, 2026 people who received insulin aspart alone or in combination with OGLDs at baseline and after 24 weeks (or last follow-up visit) were included in this analysis (Table 1). 
Table 1 Baseline patient and disease characteristics

\begin{tabular}{|c|c|c|c|c|c|c|c|c|}
\hline \multirow[t]{2}{*}{ Measurement } & \multicolumn{4}{|c|}{ Insulin-experienced } & \multicolumn{4}{|l|}{ Insulin-naive } \\
\hline & All & $\begin{array}{l}\text { No } \\
\text { OGLDs at } \\
\text { baseline }\end{array}$ & $\begin{array}{l}\text { One } \\
\text { OGLD at } \\
\text { baseline }\end{array}$ & $\begin{array}{l}\geq \text { Two } \\
\text { OGLDs } \\
\text { at baseline }\end{array}$ & All & $\begin{array}{l}\text { No } \\
\text { OGLDs } \\
\text { at baseline }\end{array}$ & $\begin{array}{l}\text { One } \\
\text { OGLD } \\
\text { at baseline }\end{array}$ & $\begin{array}{l}\geq \text { Two } \\
\text { OGLDs } \\
\text { at baseline }\end{array}$ \\
\hline$n$ (\% of cohort) & $561(100)$ & $270(48.1)$ & $187(33.3)$ & $104(18.5)$ & $1,465(100)$ & $514(35.1)$ & $568(38.8)$ & $383(26.1)$ \\
\hline $\begin{array}{l}\text { Mean (SD) age } \\
(\text { (years) })^{\mathrm{a}}\end{array}$ & $55.8(13.4)$ & $55.2(14.6)$ & $55.9(12.6)$ & $57.6(11.1)$ & $51.5(13.3)$ & $53.3(15.4)$ & $51.0(12.3)$ & $49.8(11.2)$ \\
\hline Male gender (\%) & 56.9 & 59.3 & 54.5 & 54.8 & 59.0 & 57.0 & 60.6 & 59.3 \\
\hline $\begin{array}{l}\text { Mean (SD) body } \\
\text { weight }(\mathrm{kg})^{\mathrm{b}}\end{array}$ & $68.7(14.6)$ & $67.2(15.2)$ & $69.6(14.9)$ & $71.1(11.7)$ & $67.3(12.9)$ & $65.7(13.6)$ & $67.3(12.6)$ & $69.4(12.3)$ \\
\hline $\begin{array}{l}\text { Mean (SD) BMI } \\
\left(\mathrm{kg} / \mathrm{m}^{2}\right)^{\mathrm{c}}\end{array}$ & $25.2(4.4)$ & $24.6(4.4)$ & $25.6(4.6)$ & $26.3(3.8)$ & $25.2(3.9)$ & $24.2(3.8)$ & $25.4(4.0)$ & $25.9(3.7)$ \\
\hline $\begin{array}{l}\text { Mean }(\mathrm{SD}) \\
\text { diabetes duration } \\
\text { (years) }^{\mathrm{d}}\end{array}$ & $11.2(7.0)$ & $10.6(6.9)$ & $12.0(7.5)$ & $11.2(6.0)$ & $5.8(5.2)$ & $5.2(5.7)$ & $6.3(5.2)$ & $5.9(4.6)$ \\
\hline $\begin{array}{l}\text { Mean (SD) time } \\
\text { since insulin } \\
\text { initiation (years) }\end{array}$ & $3.5(3.8)$ & $3.7(4.1)$ & $3.2(3.6)$ & $3.4(3.2)$ & $\mathrm{n} / \mathrm{a}$ & $\mathrm{n} / \mathrm{a}$ & $\mathrm{n} / \mathrm{a}$ & $\mathrm{n} / \mathrm{a}$ \\
\hline $\begin{array}{l}\text { Mean (SD) time } \\
\text { since OGLD } \\
\text { initiation (years) }\end{array}$ & $8.3(6.4)$ & $6.7(6.0)$ & $9.8(7.1)$ & $9.5(5.4)$ & $4.8(4.6)$ & $3.9(4.9)$ & $5.3(4.5)$ & $5.3(4.1)$ \\
\hline
\end{tabular}

Due to the observational nature of the study not all measures were reported/collected

$B M I$ body mass index, $O G L D s$ oral glucose-lowering drugs

${ }^{\text {a }}$ In the total, no OGLD, one OGLD and $\geq$ two OGLD groups: insulin-experienced, $n=548, n=267, n=184$ and $n=97$, respectively; insulin-naive, $n=1,418, n=506, n=540$ and $n=372$, respectively

b In the total, no OGLD, one OGLD and $\geq$ two OGLD groups: insulin-experienced, $n=526, n=258, n=182$ and $n=86$, respectively; insulin-naive, $n=1,388, n=477, n=538$ and $n=373$, respectively

c In the total, no OGLD, one OGLD and $\geq$ two OGLD groups: insulin-experienced, $n=489, n=246, n=167$ and $n=76$, respectively; insulin-naive, $n=1,312, n=452, n=506$ and $n=354$, respectively

${ }^{\mathrm{d}}$ In the total, no OGLD, one OGLD and $\geq$ two OGLD groups: insulin-experienced, $n=556, n=267, n=185$ and $n=104$, respectively; insulin-naive, $n=1,447, n=505, n=561$ and $n=381$, respectively

' In the total, no OGLD, one OGLD and $\geq$ two OGLD groups $n=500, n=242, n=160$ and $n=98$, respectively

${ }^{f}$ In the total, no OGLD, one OGLD and $\geq$ two OGLD groups: insulin-experienced, $n=530, n=254, n=174$ and $n=102$, respectively; insulin-naive, $n=1,341, n=467, n=520$ and $n=354$, respectively

Among treating physicians, the need to improve glycemic control (93.0\%) represented the predominant reason for changing/switching to insulin aspart therapy followed by the need to reduce the risk of hypoglycemia (44.9\%) and reduce variability of plasma glucose levels (27.8\%). Among insulin-experienced patients $(n=561)$, previous insulin therapies included premix human insulin (42.1\% of patients), human soluble insulin (20.7\%), insulin glargine (15.9\%), neutral protamine Hagedorn $(\mathrm{NPH}, 7.0 \%), \mathrm{NPH}$ plus human soluble insulin $(3.6 \%)$, and others such as premixed insulin lispro (10.9\%). Baseline characteristics were generally similar between patient sub-groups, although insulin-experienced patients appeared to have had longer mean diabetes duration and longer time since OGLD initiation than insulinnaive patients (Table 1). In both insulinexperienced and insulin-naive patients, metformin was the most frequently prescribed OGLD pre-study $(71 \%$ and $80 \%$ of patients, respectively), and sulfonylurea was the second most frequently prescribed (44\% and $64 \%$ of patients, respectively).

\section{Insulin Dose}

Insulin-experienced patients received a mean (standard deviation; SD) insulin dose of 0.50 
(0.29) U (or IU)/kg before entering the study. When patients switched to insulin aspart \pm OGLDs at baseline the dose ranged from 0.45 to $0.47 \mathrm{U} / \mathrm{kg}$ in the different subgroups (Fig. 1). In the insulin-naive cohort, mean (SD) insulin aspart dose was 0.40 (0.20) $\mathrm{U} / \mathrm{kg}$ at baseline (Fig. 1). Following 24 weeks' therapy with insulin aspart, there were no obvious changes from baseline in mean insulin dose in either cohort (Fig. 1).

The proportion of insulin-experienced patients receiving once daily (qd), twice daily (bid), or $\geq$ three times daily (tid) insulin aspart injections at baseline was $7.1 \%, 27.3 \%$, and $65.5 \%$, respectively. Insulin injection frequency was similar to baseline following 24 weeks of therapy with insulin aspart $(7.8 \%, 32.5 \%$, and $59.7 \%$ of patients, respectively). The proportion of insulin-naive patients receiving qd, bid, or $\geq$ tid insulin injections at baseline was 5.5\%, $40.2 \%$, and 54.3\%, respectively. Insulin injection frequency was similar to baseline following 24 weeks of insulin aspart therapy $(5.4 \%, 44.9 \%$, and $49.6 \%$ of patients, respectively).

\section{Number of OGLDs}

Most insulin-experienced and insulin-naive patients were receiving the same number of OGLDs at baseline and following 24 weeks of treatment with insulin aspart (Table 2). Most

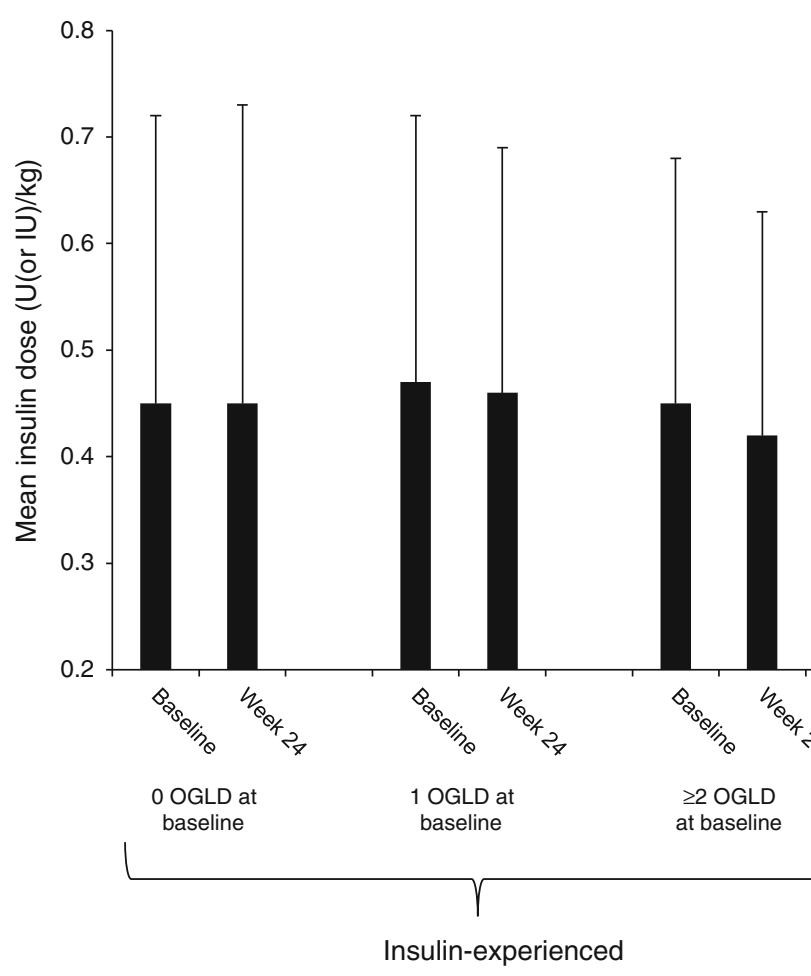

Fig. 1 Mean (SD) insulin dose received by patients at baseline and after 24 weeks on insulin aspart therapy in the $\mathrm{A}_{1}$ chieve study. Due to the observational nature of the study not all measures were reported/collected. At baseline: insulin-experienced: $n=257$ in 0 OGLD sub-group; $n=182$ in 1 OGLD sub-group; $n=86$ in $\geq 2$ OGLDs sub-group. Insulin-naive: $n=477$ in 0 OGLD sub-group; $n=536$ in 1 OGLD sub-group; $n=373$ in $\geq 2$ OGLDs sub-group. After 24 weeks: insulin-experienced: $n=178$ in 0 OGLD sub-group; $n=138$ in 1 OGLD sub-group; $n=64$ in $\geq 2$ OGLDs sub-group. Insulin-naive: $n=326$ in 0 OGLD sub-group; $n=422$ in 1 OGLD sub-group; $n=274$ in $\geq 2$ OGLDs sub-group. OGLD oral glucoselowering drug 
Table 2 Number of OGLDs taken at baseline and following 24 weeks of therapy with insulin aspart alone or with OGLDs

\begin{tabular}{|c|c|c|c|c|c|c|}
\hline \multirow{2}{*}{$\begin{array}{l}\text { Number of } \\
\text { OGLDs at } \\
24 \text { weeks }\end{array}$} & \multicolumn{3}{|c|}{ Insulin-experienced } & \multicolumn{3}{|l|}{ Insulin-naive } \\
\hline & $\begin{array}{l}\text { No OGLDs } \\
\text { at baseline }\end{array}$ & $\begin{array}{l}\text { One OGLD } \\
\text { at baseline }\end{array}$ & $\begin{array}{l}\geq \text { Two OGLDs } \\
\text { at baseline }\end{array}$ & $\begin{array}{l}\text { No OGLDs } \\
\text { at baseline }\end{array}$ & $\begin{array}{l}\text { One OGLD } \\
\text { at baseline }\end{array}$ & $\begin{array}{l}\geq \text { Two OGLDs } \\
\text { at baseline }\end{array}$ \\
\hline All, $n$ & 191 & 151 & 83 & 376 & 457 & 298 \\
\hline $\begin{array}{l}\text { No OGLDs, } n \\
(\% \text { of cohort })\end{array}$ & $157(82.2)$ & $24(15.9)$ & $1(1.2)$ & $291(77.4)$ & $49(10.7)$ & $22(7.4)$ \\
\hline $\begin{array}{r}\text { One OGLD, } n \\
(\% \text { of cohort })\end{array}$ & $27(14.1)$ & $111(73.5)$ & $15(18.1)$ & $68(18.1)$ & $286(62.6)$ & $55(18.5)$ \\
\hline $\begin{array}{l}\geq \text { Two OGLDs, } \\
n \text { (\% of cohort) }\end{array}$ & $7(3.7)$ & $16(10.6)$ & $67(80.7)$ & $17(4.5)$ & $122(26.7)$ & $221(74.2)$ \\
\hline
\end{tabular}

Due to the observational nature of the study not all measures were reported/collected

$O G L D s$ oral glucose-lowering drugs

insulin-experienced $(209 / 367,56.9 \%)$ and insulin-naive $\quad(408 / 795, \quad 51.3 \%)$ patients receiving insulin aspart injections $\geq$ tid at baseline were not taking OGLDs. However, most insulin-experienced $(22 / 40,55.0 \%)$ and insulin-naive $(43 / 82,52.4 \%)$ patients taking qd insulin aspart injections at baseline were receiving $\geq$ two OGLDs at baseline. In insulinexperienced patients receiving bid insulin aspart injections at baseline, the proportion of patients taking no OGLDs, one OGLD, or $\geq$ two OGLDs at baseline was similar (52/154, 33.8\%; 60/154, 39.0\%; and 42/154, 27.3\%, respectively). Most insulin-naive patients receiving bid insulin aspart injections were receiving one OGLD or $\geq$ two OGLDs at baseline $(270 / 588,45.9 \%$ and $221 / 588,37.6 \%$, respectively).

Metformin and/or sulfonylureas were the predominant OGLDs administered in all subgroups of patients; $>60 \%$ of patients in all subgroups were receiving metformin after 24 weeks.

\section{Serious Adverse Events}

Following 24 weeks of insulin aspart therapy, six serious adverse events (SAEs) were reported, which were considered unlikely to be related to the study treatment. In the insulin-naive cohort, three SAEs (one incident of acute cardiac failure, one malignant lung neoplasm, and one case of chronic renal failure) were reported in the group receiving no OGLDs at baseline and one SAE (vascular stenosis) was reported in the group receiving one OGLD at baseline; two deaths (one acute cardiac failure and the other malignant lung neoplasm) were reported in the insulin-naive cohort. In the insulin-experienced cohort, two SAEs were reported in the group receiving no OGLDs at baseline: upper gastrointestinal hemorrhage and hepatic coma. No other SAEs were reported.

\section{Hypoglycemia Events}

The proportion of insulin-experienced and insulin-naive patients reporting at least one hypoglycemia event was significantly decreased from baseline following 24 weeks of treatment with insulin aspart in patients receiving bid or tid insulin injections (Table 3). The proportion of patients reporting at least one hypoglycemia event did not significantly change between baseline and 24 weeks in patients receiving qd or four times daily (qid) insulin injections 
(Table 3). There was no obvious effect of insulin injection frequency on the proportion of patients experiencing nocturnal hypoglycemia events at 24 weeks in insulin-experienced and insulin-naive patients (Table 3).

The proportion of patients reporting at least one hypoglycemia event was significantly decreased from baseline following 24 weeks of treatment with insulin aspart, irrespective of prior insulin experience and the number of OGLDs received at baseline (Table 4); the exception was no significant change between baseline and 24 weeks in insulin-naive patients who were receiving no OGLDs at baseline. The proportion of patients reporting at least one nocturnal hypoglycemia event was significantly decreased from baseline to 24 weeks irrespective of prior insulin experience and the number of OGLDs received at baseline; the exceptions were no change between baseline and 24 weeks in insulin-experienced patients taking $\geq$ two OGLDs at baseline, and insulin-naive patients taking no OGLDs at baseline (Table 4).

At 24 weeks, no major hypoglycemia events were reported in the insulin-experienced or insulin-naive cohorts and the risk of nocturnal hypoglycemia was reduced to $<0.6$ events/ person-year, irrespective of baseline insulin

Table 3 Safety outcomes before and after 24 weeks of treatment with insulin aspart alone or with OGLDs according to baseline insulin injection frequency

\begin{tabular}{|c|c|c|c|c|c|c|c|c|}
\hline \multirow[t]{3}{*}{ Measurement } & \multicolumn{8}{|c|}{ \% Patients with at least one event (event/person-year) } \\
\hline & \multicolumn{4}{|c|}{ Insulin-experienced } & \multicolumn{4}{|c|}{ Insulin-naive } \\
\hline & $\begin{array}{l}\text { Once } \\
\text { daily }\end{array}$ & $\begin{array}{l}\text { Twice } \\
\text { daily }\end{array}$ & $\begin{array}{l}\text { Three times } \\
\text { daily }\end{array}$ & $\begin{array}{l}\text { Four times } \\
\text { daily }\end{array}$ & $\begin{array}{l}\text { Once } \\
\text { daily }\end{array}$ & $\begin{array}{l}\text { Twice } \\
\text { daily }\end{array}$ & $\begin{array}{l}\text { Three times } \\
\text { daily }\end{array}$ & $\begin{array}{l}\text { Four times } \\
\text { daily }\end{array}$ \\
\hline \multicolumn{9}{|c|}{ Hypoglycemia (overall) } \\
\hline Baseline & $10.0(2.3)$ & $16.2(4.5)$ & $28.1(10.8)$ & $22.5(19.2)$ & $2.4(0.5)$ & $12.8(3.3)$ & $5.1(1.7)$ & $2.3(0.3)$ \\
\hline$n$ & 40 & 154 & 327 & 40 & 82 & 588 & 751 & 44 \\
\hline 24 weeks & $0(0)$ & $7.8(1.3)^{*}$ & $8.1(1.9)^{* * *}$ & $14.3(2.3)$ & $1.5(0.6)$ & $2.1(0.5)^{* * *}$ & $3.5(1.2)^{*}$ & $4.0(0.5)$ \\
\hline$n$ & 33 & 128 & 236 & 28 & 66 & 466 & 574 & 25 \\
\hline \multicolumn{9}{|c|}{ Hypoglycemia (major $)^{a}$} \\
\hline Baseline & $2.5(0.3)$ & $5.2(1.0)$ & $5.8(1.7)$ & $7.5(1.0)$ & $0(0)$ & $1.7(0.2)$ & $0.7(0.1)$ & $0(0)$ \\
\hline 24 weeks & $0(0)^{\mathrm{b}}$ & $0(0)^{* *}$ & $0(0)^{* * *}$ & $0(0)$ & $0(0)^{\mathrm{c}}$ & $0(0)$ & $0(0)^{*}$ & $0(0)^{\mathrm{c}}$ \\
\hline \multicolumn{9}{|c|}{ Hypoglycemia (nocturnal) } \\
\hline Baseline & $2.5(0.3)$ & $7.1(1.4)$ & $14.7(3.0)$ & $15.0(8.5)$ & $0(0)$ & $8.3(1.3)$ & $1.3(0.3)$ & $0(0)$ \\
\hline 24 weeks & $0(0)$ & $2.3(0.3)$ & $0(0)^{* * *}$ & $3.6(0.5)$ & $1.5(0.2)$ & $0.6(0.1)^{* * *}$ & $0.3(0.1)$ & $0(0)^{\mathrm{c}}$ \\
\hline
\end{tabular}

Due to the observational nature of the study not all measures were reported/collected

${ }^{* * *} p<0.001$ vs. baseline

** $p<0.01$ vs. baseline

${ }^{*} p<0.05$ vs. baseline

${ }^{a} n$ for each cohort same as for hypoglycemia (overall) data

b Statistical analysis could not be performed with McNemar's test as patients reporting hypoglycemia at baseline were missing hypoglycemia data for 24 weeks

c No hypoglycemia events were reported at baseline and 24 weeks; therefore statistical analysis could not be conducted 
Table 4 Safety outcomes before and after 24 weeks of treatment with insulin aspart alone or with OGLDs according to OGLDs taken at baseline

\begin{tabular}{|c|c|c|c|c|c|c|c|c|}
\hline \multirow[t]{3}{*}{ Measurement } & \multicolumn{8}{|c|}{$\%$ Patients with at least one event (event/person-year) } \\
\hline & \multicolumn{4}{|c|}{ Insulin-experienced } & \multicolumn{4}{|c|}{ Insulin-naive } \\
\hline & All & $\begin{array}{l}\text { No } \\
\text { OGLDs } \\
\text { at baseline }\end{array}$ & $\begin{array}{l}\text { One } \\
\text { OGLD at } \\
\text { baseline }\end{array}$ & $\begin{array}{l}\geq \text { Two } \\
\text { OGLDs at } \\
\text { baseline }\end{array}$ & All & $\begin{array}{l}\text { No } \\
\text { OGLDs at } \\
\text { baseline }\end{array}$ & $\begin{array}{l}\text { One } \\
\text { OGLD at } \\
\text { baseline }\end{array}$ & $\begin{array}{l}\geq \text { Two } \\
\text { OGLDs at } \\
\text { baseline }\end{array}$ \\
\hline \multicolumn{9}{|c|}{ Hypoglycemia (overall) } \\
\hline Baseline & $23.2(9.1)$ & $26.3(11.4)$ & $20.3(6.8)$ & $20.2(7.1)$ & $7.9(2.2)$ & $4.9(1.8)$ & $7.7(1.8)$ & $12.3(3.5)$ \\
\hline$n$ & 561 & 270 & 187 & 104 & 1,465 & 514 & 568 & 383 \\
\hline 24 weeks & $7.8(1.6)^{* * *}$ & $9.4(2.2)^{* * *}$ & $6.6(1.4)^{* * *}$ & $6.0(0.8)^{*}$ & $2.8(0.9)^{* * *}$ & $4.3(1.4)$ & $2.6(0.8)^{* * *}$ & $1.3(0.4)^{* * *}$ \\
\hline$n$ & 425 & 191 & 151 & 83 & 1,131 & 376 & 457 & 298 \\
\hline \multicolumn{9}{|c|}{ Hypoglycemia (major) ${ }^{a}$} \\
\hline Baseline & $5.5(1.3)$ & $6.3(1.8)$ & $3.2(0.6)$ & $7.7(1.4)$ & $1.0(0.2)$ & $0.4(0.1)$ & $0.7(0.1)$ & $2.3(0.3)$ \\
\hline 24 weeks & $0(0)^{* * *}$ & $0(0)^{* * *}$ & $0(0)^{*}$ & $0(0)^{*}$ & $0(0)^{* *}$ & $0(0)$ & $0(0)^{*}$ & $0(0)$ \\
\hline \multicolumn{9}{|c|}{ Hypoglycemia (nocturnal) ${ }^{a}$} \\
\hline Baseline & $11.8(2.8)$ & $14.4(3.2)$ & $10.2(2.4)$ & $7.7(2.1)$ & $4.0(0.7)$ & $1.0(0.3)$ & $4.9(0.6)$ & $6.8(1.2)$ \\
\hline 24 weeks & $0.9(0.1)^{* * *}$ & $0.5(0.1)^{* * *}$ & $1.3(0.2)^{* *}$ & $1.2(0.2)$ & $0.5(0.1)^{* * *}$ & $1.1(0.2)$ & $0.4(0.1)^{* * *}$ & $0(0)^{* * *}$ \\
\hline
\end{tabular}

Due to the observational nature of the study not all measures were reported/collected

$O G L D s$ oral glucose-lowering drugs

${ }^{* * *} p<0.001$ vs. baseline

${ }^{* *} p<0.01$ vs. baseline

${ }^{*} p<0.05$ vs. baseline

a $n$ for each cohort same as for hypoglycemia (overall) data

injection frequency and number of OGLDs received. No other adverse reactions or serious adverse reactions were reported that were considered possibly related to the study treatment.

\section{Glucose Control}

There were statistically significant improvements in measures of blood glucose control (PPG, FPG and $\mathrm{HbA}_{1 \mathrm{c}}$ ) after 24 weeks of treatment with insulin aspart regardless of concomitant OGLD use $(p<0.001$ versus baseline for all measures across all sub-groups in both the insulin-naive and insulin- experienced cohorts; Table 5). There were no obvious differences in these parameters between sub-groups (Table 5).

\section{Body Weight}

Body weight remained stable throughout the study for insulin-experienced patients, irrespective of the number of OGLDs received (Table 5). In the insulin-naive cohort, there was a significant mean weight gain $(0.6 \mathrm{~kg})$ from baseline at 24 weeks in patients receiving no OGLDs at baseline and a significant weight loss $(-0.2 \mathrm{~kg})$ in the sub-group receiving $\geq$ two OGLDs at baseline (Table 5). 
Table 5 Effectiveness outcomes before and after 24 weeks of treatment with insulin aspart alone or with OGLDs

\begin{tabular}{|c|c|c|c|c|c|c|c|c|}
\hline \multirow[t]{2}{*}{ Measurement } & \multicolumn{4}{|c|}{ Insulin-experienced } & \multicolumn{4}{|l|}{ Insulin-naive } \\
\hline & All & $\begin{array}{l}\text { No } \\
\text { OGLDs at } \\
\text { baseline }\end{array}$ & $\begin{array}{l}\text { One } \\
\text { OGLD at } \\
\text { baseline }\end{array}$ & $\begin{array}{l}\geq \text { Two } \\
\text { OGLDs at } \\
\text { baseline }\end{array}$ & All & $\begin{array}{l}\text { No } \\
\text { OGLDs at } \\
\text { baseline }\end{array}$ & $\begin{array}{l}\text { One } \\
\text { OGLD at } \\
\text { baseline }\end{array}$ & $\begin{array}{l}\geq \text { Two } \\
\text { OGLDs at } \\
\text { baseline }\end{array}$ \\
\hline \multicolumn{9}{|c|}{ Mean $(S D) H b A_{1 c}(\%)$} \\
\hline Baseline & $9.1(2.1)$ & $9.0(2.2)$ & $9.3(2.1)$ & $9.1(1.6)$ & $9.5(1.9)$ & $9.4(2.2)$ & $9.7(1.9)$ & $9.3(1.5)$ \\
\hline 24 weeks & $7.4(1.1)$ & $7.4(1.2)$ & $7.5(1.1)$ & $7.5(1.0)$ & $7.2(1.1)$ & $7.2(1.1)$ & $7.2(1.1)$ & $7.3(1.1)$ \\
\hline $\begin{array}{l}\text { Change after } \\
24 \text { weeks }\end{array}$ & $-1.7(1.9)^{* * *}$ & $-1.6(2.1)^{* * *}$ & $-1.9(1.9)^{* * *}$ & $-1.7(1.6)^{* * *}$ & $-2.2(2.0)^{* * *}$ & $-2.1(2.2)^{* * *}$ & $-2.4(2.0)^{* * *}$ & $-2.1(1.8)^{* * *}$ \\
\hline$n$ & 279 & 123 & 101 & 55 & 794 & 226 & 309 & 259 \\
\hline \multicolumn{9}{|c|}{ Mean $(S D) H b A_{1 c}(\mathrm{mmol} / \mathrm{mol})$} \\
\hline Baseline & $76(23)$ & $75(24)$ & $78(23)$ & $76(17)$ & $80(21)$ & $79(24)$ & $83(21)$ & $78(16)$ \\
\hline 24 weeks & $57(12)$ & $57(13)$ & $58(12)$ & $58(11)$ & $55(12)$ & $55(12)$ & $55(12)$ & $56(12)$ \\
\hline $\begin{array}{l}\text { Change after } \\
24 \text { weeks }\end{array}$ & $-19(21)^{* * *}$ & $-17(23)^{* * *}$ & $-21(21)^{* * *}$ & $-19(17)^{* * *}$ & $-24(22)^{* * *}$ & $-23(24)^{* * *}$ & $-26(22)^{* * *}$ & $-23(20)^{* * *}$ \\
\hline$n$ & 279 & 123 & 101 & 55 & 794 & 226 & 309 & 259 \\
\hline \multicolumn{9}{|c|}{ Mean (SD) FPG (mmol/l) } \\
\hline Baseline & $9.9(3.7)$ & $9.6(3.9)$ & $10.1(3.4)$ & $10.0(3.7)$ & $10.8(3.5)$ & $10.2(3.6)$ & $11.7(3.5)$ & $10.3(2.9)$ \\
\hline 24 weeks & $7.1(2.0)$ & $7.1(2.1)$ & $7.0(1.9)$ & $7.3(2.3)$ & $7.4(2.0)$ & $7.1(1.7)$ & $7.9(2.3)$ & $7.0(1.6)$ \\
\hline $\begin{array}{l}\text { Change after } \\
24 \text { weeks }\end{array}$ & $-2.8(3.6)^{* * *}$ & $-2.5(3.9)^{* * *}$ & $-3.1(3.2)^{* * *}$ & $-2.7(3.3)^{* * *}$ & $-3.4(3.0)^{* * *}$ & $-3.1(3.3)^{* * *}$ & $-3.8(3.0)^{* * *}$ & $-3.2(2.7)^{* * *}$ \\
\hline$n$ & 329 & 155 & 119 & 55 & 990 & 303 & 412 & 275 \\
\hline \multicolumn{9}{|c|}{ Mean (SD) PPG (mmol/l) } \\
\hline Baseline & $13.4(4.5)$ & $13.1(4.8)$ & $13.6(4.1)$ & $14.2(4.3)$ & $15.8(4.7)$ & $14.9(5.2)$ & $16.5(4.4)$ & $16.0(4.1)$ \\
\hline 24 weeks & $9.9(2.9)$ & $9.7(2.7)$ & $10.0(3.0)$ & $10.4(3.3)$ & $10.1(3.2)$ & $9.2(2.9)$ & $10.7(3.4)$ & $10.3(2.8)$ \\
\hline $\begin{array}{l}\text { Change after } \\
24 \text { weeks }\end{array}$ & $-3.5(4.2)^{* * *}$ & $-3.4(4.2)^{* * *}$ & $-3.6(3.8)^{* * *}$ & $-3.8(5.1)^{* * *}$ & $-5.8(4.5)$ & $-5.7(5.0)^{* * *}$ & $-5.8(4.3)^{* * *}$ & $-5.7(4.1)^{* * *}$ \\
\hline$n$ & 262 & 119 & 105 & 38 & 735 & 255 & 316 & 164 \\
\hline \multicolumn{9}{|c|}{ Mean $(S D)$ body weight $(\mathrm{kg})$} \\
\hline Baseline & $68.6(13.8)$ & $67.4(13.7)$ & $68.9(14.7)$ & $71.3(11.9)$ & $66.9(12.4)$ & $65.1(12.8)$ & $66.9(11.6)$ & $69.1(12.7)$ \\
\hline 24 weeks & $68.6(13.1)$ & $67.6(12.9)$ & $68.9(14.2)$ & $70.8(10.7)$ & $67.1(11.8)$ & $65.7(12.0)$ & $67.0(11.1)$ & $68.9(12.4)$ \\
\hline $\begin{array}{l}\text { Change after } \\
24 \text { weeks }\end{array}$ & $0.0(2.6)$ & $0.2(2.6)$ & $0.0(2.5)$ & $-0.5(2.4)$ & $0.2(2.8)$ & $0.6(3.7)^{* *}$ & $0.1(2.4)$ & $-0.2(1.8)^{*}$ \\
\hline$n$ & 377 & 176 & 137 & 64 & 999 & 313 & 413 & 273 \\
\hline \multicolumn{9}{|c|}{ Mean (SD) HRQoL (UK VAS) } \\
\hline Baseline & $0.672(0.278)$ & $0.706(0.287)$ & $0.694(0.253)$ & $0.567(0.277)$ & $0.621(0.304)$ & $0.768(0.258)$ & $0.577(0.314)$ & $0.513(0.271)$ \\
\hline 24 weeks & $0.840(0.163)$ & $0.846(0.180)$ & $0.822(0.147)$ & $0.859(0.152)$ & $0.816(0.162)$ & $0.863(0.159)$ & $0.798(0.163)$ & $0.791(0.154)$ \\
\hline $\begin{array}{l}\text { Change after } \\
24 \text { weeks }\end{array}$ & $\begin{array}{l}0.168 \\
\quad(0.260)^{* * *}\end{array}$ & $\begin{array}{l}0.141 \\
\quad(0.268)^{* * *}\end{array}$ & $\begin{array}{l}0.128 \\
\quad(0.246)^{* * *}\end{array}$ & $\begin{array}{l}0.292 \\
\quad(0.230)^{* * *}\end{array}$ & $\begin{array}{l}0.195 \\
\quad(0.295)^{* * *}\end{array}$ & $\begin{array}{l}0.095 \\
\quad(0.264)^{* * *}\end{array}$ & $\begin{array}{l}0.220 \\
(0.304)^{* * *}\end{array}$ & $\begin{array}{l}0.277 \\
\quad(0.281)^{* * *}\end{array}$ \\
\hline$n$ & 331 & 145 & 116 & 70 & 926 & 293 & 399 & 234 \\
\hline
\end{tabular}

Due to the observational nature of the study not all measures were reported/collected

$F P G$ fasting plasma glucose, pre-breakfast measurement, $H b A_{1 c}$ glycated hemoglobin, $H R Q L L$ health-related quality of life, $O G L D s$ oral glucose-lowering drugs, $P P G$ post-prandial plasma glucose, 90-120 min after the beginning of breakfast, $V A S$ visual analog scale

${ }^{* * *} p<0.001$ vs. baseline

${ }^{* *} p<0.01$ vs. baseline

${ }^{*} p<0.05$ vs. baseline 


\section{Health-Related Quality of Life}

Following 24 weeks of insulin aspart therapy, statistically significant improvements from baseline in UK VAS scores were observed in all sub-groups of insulin-experienced and insulinnaive patients $(p<0.001$ versus baseline for all measures across all sub-groups in both the insulin-naive and insulin-experienced cohorts; Table 5).

\section{DISCUSSION}

In this sub-analysis of the $A_{1}$ chieve study, patients who switched to/initiated therapy with insulin aspart \pm OGLDs, as part of routine clinical practice, experienced statistically significant improvements in $\mathrm{HbA}_{1 \mathrm{c}}$, FPG, and PPG following 24 weeks of treatment. This was achieved irrespective of previous insulin experience and the number of concomitant OGLDs received. Whereas the reduction in PPG is expected with the use of insulin aspart, the reduction in FPG level is not necessarily anticipated with the use of prandial insulin only. However, although few studies have examined the effectiveness of bolus-only insulin aspart, particularly as add-on to OGLDs, available data are in line with current findings $[22,28,29]$. In the INSTIGATE (INSulin TItration-GAining an understanding of the burden of Type 2 diabetes in Europe) observational study, for example, reductions in FPG were observed following 24 months of prandial insulin therapy \pm OGLDs, and reductions in $\mathrm{HbA}_{1 \mathrm{c}}(-2.2 \%)$ were similar to those reported here [29].

Overall, $52 \%$ of the patients who switched to/initiated therapy with insulin aspart alone or in combination with OGLDs continued on this insulin regimen for the duration of the study. In the INSTIGATE study, $31 \%$ of the total cohort who were receiving prandial insulin at baseline continued to be managed on this regimen after 2 years of treatment [29]. These data suggest that a prandial insulin regimen is able to effectively control glucose levels over an extended time in many patients.

While weight increases have been reported with the longer-term use of prandial insulin [22], weight remained stable from baseline to 24 weeks in this study, irrespective of prior insulin experience and concomitant OGLD use. There was a significant, but numerically small, weight gain $(0.6 \mathrm{~kg})$ in a single sub-group; the insulin-naive cohort receiving no OGLDs at baseline.

Importantly, significant improvements in glycemic control with insulin aspart were also achieved without increasing the risk of hypoglycemia events irrespective of insulin injection frequency and OGLD use. There were significant reductions in the proportion of patients receiving bid or tid insulin aspart injections who reported hypoglycemia events regardless of prior insulin experience. This is pertinent given the greater risk of hypoglycemia events that might be expected with increasing injection frequency. While there were numerical reductions in the proportions of insulin-experienced patients experiencing hypoglycemia events in the groups receiving qd or qid insulin injections, these might have failed to reach statistical significance due to low patient numbers. The proportion of patients reporting hypoglycemia events in the insulinnaive group not receiving OGLDs at baseline did not significantly change between baseline and 24 weeks. Improvements in hypoglycemia were also achieved despite a high proportion of patients in the insulin-experienced and insulinnaive cohorts receiving sulfonylureas at 24 weeks $(35.4 \%$ and $41.4 \%$ of patients, respectively). There were no reports of major 
hypoglycemia events in the 4 weeks preceding the assessment at 24 weeks, and nocturnal hypoglycemia was reduced to low rates $(<0.6$ events/person-year) in all sub-groups of patients, as would be expected from the clinical profile of insulin aspart [10]. While guidelines recommend discontinuation of sulfonylureas on commencement of prandial insulin therapy to minimize the risk of hypoglycemia episodes, this does not always occur in practice [30].

The limitations of the $A_{1}$ chieve study design have been discussed previously [20] and include the following: the lack of randomization, the absence of a control arm, and the absence of control for concomitant medication, dietary or lifestyle changes. In addition, the reporting of hypoglycemia events was based on patient recall of events over the preceding 4 weeks; although unlikely to affect the recording of major hypoglycemia episodes, this may have resulted in underestimation of mild events. Another limitation was that dose titration to optimize glycemic control was not a stipulation of this observational study and, therefore, glycemic control could have been better than recorded. A further improvement in glycemic control with up titration of insulin dose would appear realistic given the low rate of hypoglycemia events. Statistical power may also be limited in this sub-analysis as it includes a small proportion of the total $\mathrm{A}_{1}$ chieve cohort of patients. Despite these limitations, the results from this analysis are highly informative, given that they are derived from a large number of patients, and also from a wide geographical range, including many less developed world economies, whose standards of clinical practice with respect to type 2 diabetes mellitus are less well documented.

The $A_{1}$ chieve study demonstrated that some healthcare professionals prefer to start patients on insulin therapy with prandial rather than basal insulin [20], and add basal insulin when required. Our sub-analysis shows that this strategy can be effective and well tolerated for the management of type 2 diabetes mellitus in patients poorly controlled on other treatment regimens. These findings warrant further investigation in clinical trials, given recent calls for an individualized approach to initiation of insulin regimens in people with type 2 diabetes mellitus and sub-optimal glycemic control [31].

\section{ACKNOWLEDGMENTS}

The $A_{1}$ chieve study and this manuscript were funded by Novo Nordisk A/S (Bagsvaerd, Denmark). Editorial assistance on this manuscript was provided by Martin Gilmour and Daniella Otway at ESP Bioscience (Crowthorne, UK), funded by Novo Nordisk A/S. Jian-Wen Chen is the guarantor for this article, and takes responsibility for the integrity of the work as a whole.

Conflict of interest. Hoosen Randeree has no conflicts of interest to declare. Andreas Liebl received honoraria from Novo Nordisk, Eli Lilly, Astra Zeneca, Roche, MSD, and Medtronic for giving lectures, conducting scientific studies, and serving as an advisory board member. Issam Hajjaji has no conflicts of interest to declare. Mohammad Khamseh received funding from Novo Nordisk for a clinical trial. Lenita Zajdenverg is a Novo Nordisk advisory board member. Jian-Wen Chen is an employee of Novo Nordisk A/S. Jihad Haddad is an advisory board member for Novo Nordisk and Merck, and is on the speaker's bureau for Novo Nordisk, Merck, Novartis, Astra Zeneca, MSD, and Minarini. 
Compliance with ethics guidelines. All participants gave informed consent and were free to withdraw from the study at any time. The study was conducted in accordance with the Declaration of Helsinki of 1964, as revised in 2008 and Guidelines for Good Pharmacoepidemiology Practice.

Open Access. This article is distributed under the terms of the Creative Commons Attribution Noncommercial License which permits any noncommercial use, distribution, and reproduction in any medium, provided the original author(s) and the source are credited.

\section{REFERENCES}

1. Cheng D. Prevalence, predisposition and prevention of type II diabetes. Nutr Metab (Lond). 2005;18:29.

2. Whiting DR, Guariguata L, Weil C, Shaw J. IDF diabetes atlas: global estimates of the prevalence of diabetes for 2011 and 2030. Diabetes Res Clin Pract. 2011;94:311-21.

3. Wild S, Roglic G, Green A, Sicree R, King H. Global prevalence of diabetes: estimates for the year 2000 and projections for 2030. Diabetes Care. 2004;27:1047-53.

4. Ramachandran A, Snehalatha C, Shetty AS, Nanditha A. Trends in prevalence of diabetes in Asian countries. World J Diabetes. 2012;3:110-7.

5. Lam DW, LeRoith D. The worldwide diabetes epidemic. Curr Opin Endocrinol Diabetes Obes. 2012;19:93-6.

6. International Diabetes Federation. Guideline for Management of PostMeal Glucose in Diabetes. Available at: http://www.idf.org/sites/default/ files/postmeal\%20glucose\%20guidelines.pdf. Accessed 30 Aug 2012.

7. Turner RC, Cull CA, Frighi V, Holman RR. Glycemic control with diet, sulfonylurea, metformin, or insulin in patients with type 2 diabetes mellitus: progressive requirement for multiple therapies (UKPDS 49). UK Prospective Diabetes Study (UKPDS) Group. JAMA. 1999;281:2005-12.
8. Groop LC. Sulfonylureas in NIDDM. Diabetes Care. 1992;15:737-54.

9. Lindholm A, Jacobsen LV. Clinical pharmacokinetics and pharmacodynamics of insulin aspart. Clin Pharmacokinet. 2001;40:641-59.

10. Heller SR, Colagiuri S, Vaaler $S$, et al. Hypoglycaemia with insulin aspart: a doubleblind, randomised, crossover trial in subjects with type 1 diabetes. Diabet Med. 2004;21:769-75.

11. Freeman JS. Insulin analog therapy: improving the match with physiologic insulin secretion. J Am Osteopath Assoc. 2009;109:26-36.

12. Home PD. The pharmacokinetics and pharmacodynamics of rapid-acting insulin analogues and their clinical consequences. Diabetes Obes Metab. 2012;14:780-8.

13. Brunner GA, Hirschberger S, Sendlhofer G, et al. Post-prandial administration of the insulin analogue insulin aspart in patients with type 1 diabetes mellitus. Diabet Med. 2000;17:371-5.

14. Home PD, Lindholm A, Hylleberg B, Round P. Improved glycemic control with insulin aspart: a multicenter randomized double-blind crossover trial in type 1 diabetic patients. UK Insulin Aspart Study Group. Diabetes Care. 1998;21:1904-9.

15. Home PD, Lindholm A, Riis A. Insulin aspart vs. human insulin in the management of long-term blood glucose control in type 1 diabetes mellitus: a randomized controlled trial. Diabet Med. 2000;17:762-70.

16. Lindholm A, McEwen J, Riis AP. Improved postprandial glycemic control with insulin aspart. A randomized double-blind cross-over trial in type 1 diabetes. Diabetes Care. 1999;22:801-5.

17. Perriello G, Pampanelli S, Porcellati F, et al. Insulin aspart improves meal time glycaemic control in patients with type 2 diabetes: a randomized, stratified, double-blind and cross-over trial. Diabet Med. 2005;22:606-11.

18. Rosenfalck AM, Thorsby P, Kjems L, et al. Improved postprandial glycaemic control with insulin aspart in type 2 diabetic patients treated with insulin. Acta Diabetol. 2000;37:41-6.

19. International Diabetes Federation. IDF Clinical Guidelines Task Force. Global guideline for type 2 diabetes. Brussels: International Diabetes Federation; 2012.

20. Home P, Naggar NE, Khamseh $M$, et al. An observational non-interventional study of people 
with diabetes beginning or changed to insulin analogue therapy in non-Western countries: the $\mathrm{A}_{1}$ chieve study. Diabetes Res Clin Pract. 2011;94:352-63.

21. Scherbaum WA, Haak T. Medical antihyperglycaemic treatment of diabetes mellitus type 2. Update of the evidence-based guideline of the German Diabetes Association. Exp Clin Endocrinol Diabetes. 2009;117(9):522-57.

22. Holman RR, Thorne KI, Farmer AJ, et al. Addition of biphasic, prandial, or basal insulin to oral therapy in type 2 diabetes. N Engl J Med. 2007;357:1716-30.

23. World Medical Association. Declaration of Helsinki-ethical principles for medical research involving human subjects 2008. Available at: http:/www.riip-influenza.org/wp-content/uploads/ 2011/08/Helsinki-2008-EN.pdf. Accessed 8 Nov 2011.

24. International Society for Pharmacoepidemiology. Guidelines for Good Pharmacoepidemiology Practices (GPP). Revision 2, April 2007. Available at: http://www.pharmacoepi.org/resources/guidelines_ 08027.cfm. Accessed 22 May 2013.

25. The EuroQol Group: EuroQol-a new facility for the measurement of health-related quality of life. Health Policy. 1990;16:199-208.
26. Dolan P. Modeling valuations for EuroQol health states. Med Care. 1997;35:1095-108.

27. Shah S, Zilov A, Malek R, Soewondo P, Bech O, Litwak L. Improvements in quality of life associated with insulin analogue therapies in people with type 2 diabetes: results from the $A_{1}$ chieve observational study. Diabetes Res Clin Pract. 2011;94:364-70.

28. Lasserson DS, Glasziou P, Perera R, Holman RR, Farmer AJ. Optimal insulin regimens in type 2 diabetes mellitus: systematic review and metaanalyses. Diabetologia. 2009;52:1990-2000.

29. Liebl A, Jones S, Goday A, et al. Clinical outcomes after insulin initiation in patients with type 2 diabetes: 24-month results from INSTIGATE. Diabetes Ther. 2012;3:9.

30. Inzucchi SE, Bergenstal RM, Buse JB, et al. Management of hyperglycemia in type 2 diabetes: a patient-centered approach: position statement of the American Diabetes Association (ADA) and the European Association for the Study of Diabetes (EASD). Diabetes Care. 2012;35:1364-79.

31. Schernthaner G, Barnett AH, Betteridge DJ, et al. Is the ADA/EASD algorithm for the management of type 2 diabetes (January 2009) based on evidence or opinion? A critical analysis. Diabetologia. 2010;53:1258-69. 